\title{
Study on the influence of geological and anthropogenic activities on hydrogeochemical and isotopic characteristics in a typical pre-urban watershed
}

\author{
FAN LE ${ }^{1,2}$, XIAOHONG RUAN ${ }^{1,2, *}$, RONGFU LI ${ }^{1,2}$ \\ ${ }^{1}$ Department of HydroSciences, School of Earth Sciences \\ and Engineering, Nanjing University, Nanjing, China \\ ${ }^{2}$ MOE Key Laboratory of Surficial Geochemistry, Nanjing \\ University, Nanjing, China
}

Zhangxi Watershed is a typical pre-urban critical zone in the south-east hilly terrain of the Yangtze River delta. There are two types of bedrock in the basin, saying acidic volcanic rock in the upstream and glutenite in the downstream. In this study, a total of 24 surface water samples and 7 groundwater samples were collected in December 2018, April 2019 and October 2019. Hydrogeochemical characteristic and multiple isotopic compositions $\left(\delta \mathrm{D} 、 \delta^{18} \mathrm{O}, \delta^{15} \mathrm{~N} 、 \delta^{18} \mathrm{O}_{-} \mathrm{NO}_{3}{ }^{-}\right.$) were analyzed to quantify the interaction between surface water and groundwater, and to elucidate the distribution and sources of nitrogen along the hydrological path. The results show that: (1) Closely hydraulic connection exists between surface water, shallow groundwater and fissure water due to the similar $\delta \mathrm{D}$ and $\delta^{18} \mathrm{O}$ values. A three-component mixing model was used to estimate the contribution of different water sources to surface water, among which groundwater contributes the most $(45.8 \%)$, followed by soil water $(29 \%)$ and meteoric precipitation (25.2\%). (2) The hydrogeochemical type is Ca$\mathrm{HCO}_{3}$ for surface water and shallow groundwater, and Na$\mathrm{HCO}_{3}$ for fissure water in volcanic and glutenite bedrock. Measured $\delta \mathrm{D}$ and $\delta^{18} \mathrm{O}$ values in surface water have no significant change along the flow path, while the $\delta^{15} \mathrm{~N}_{-} \mathrm{NO}_{3}{ }^{-}$ values vary significantly. The $\delta^{15} \mathrm{~N}_{-} \mathrm{NO}_{3}{ }^{-}$value of river water through farmland and villages $\left(5.20 \%{ }_{0} \pm 0.62 \%\right)$ is notably higher than that of natural wood $\left(1.63 \%_{0} \pm 1.29 \%\right)$. (3) According to the values of $\delta^{15} \mathrm{~N}$ and $\delta^{18} \mathrm{O}$, nitrate in surface water mainly derives from chemical fertilizer and soil organic nitrogen, while nitrate in shallow groundwater derives from organic fertilizer. Besides, denitrification may have occurred in fissure water due to the low nitrate concentration $(0.15 \pm 0.08 \mathrm{mg} / \mathrm{L})$ and synchronous enrichment of ${ }^{15} \mathrm{~N}$ and ${ }^{18} \mathrm{O}$ of nitrate. The results above show that the influence of anthropogenic activities on the hydrogeochemical cycle in Zhangxi watershed is greater than that of natural geological factors, which will be valuable for the protection of water resources in pre-urban critical zone. 